\title{
THE CEREBRO-SPINAL FEVER EPIDEMIC OF 1917 AT X DEPOT.
}

\author{
By J. A. GLOVER, M.D., D.P.H., Captain R.A.M.C. \\ (With $3^{\circ}$ Charts.)
}

...... its (i.e. the then undiscovered meningococcus) selective property for the meninges must certainly be greatly influenced by the insanitary atmosphere that always hovers over large collections of men, by the fatigue, and by the depression of rigid discipline, and by the impaired vitality ensuing from the first entry into a monotonous existence.

Col. Diммоск, I.M.S.

Written in 1884 on an epidemic of cerebro-spinal fever in India.

\section{GENERAL DESCRIPTION.}

SET 600 feet above sea level, on the highest part of a chalk plateau, and surrounded by open common lands, the depot is a pleasant spot in summer. Unprotected in any way from the east, or indeed from any other wind, there are few bleaker spots in the south of England in the frosts and blizzards of such a winter as that of 1917. Small wonder then if recruit and returned Expeditionary man alike felt justified when, in draughty huts, they closed all windows as tightly as the contractors would permit, and enjoyed the very closeness of their overcrowded atmosphere.

It is an interesting fact that if the beds of a heavily infected hut be charted, the carriers lie usually thickest round the stove, no doubt owing to the nightly gathering round the only warm, and certainly the stuffiest portion of the hut.

In peace-time the depot is housed entirely in its permanent barrackrooms and has a normal population of some 800 men. Since war began, its accommodation has been increased to fivefold by huts, and the population has sometimes exceeded sevenfold its peace population.

The depot receives straight from civil life the recruits of five infantry regiments, hereinafter called $\mathrm{A}, \mathrm{B}, \mathrm{C}, \mathrm{D}, \mathrm{E}$, in order of both seniority and strength. These recruits it trains for three months intensively, 
Chart A. Cerebro-Spinal Fever. 1917 Epidemic in " $X$ " Depot.

Percentage Carrier Rate-shaded columns-shown in relation to:

1. Incidence of cases-black columns $\square=1$ case.

2. Ration Strength of Depot shown thus -

3. Mean Weekly Temperature-broken line thus

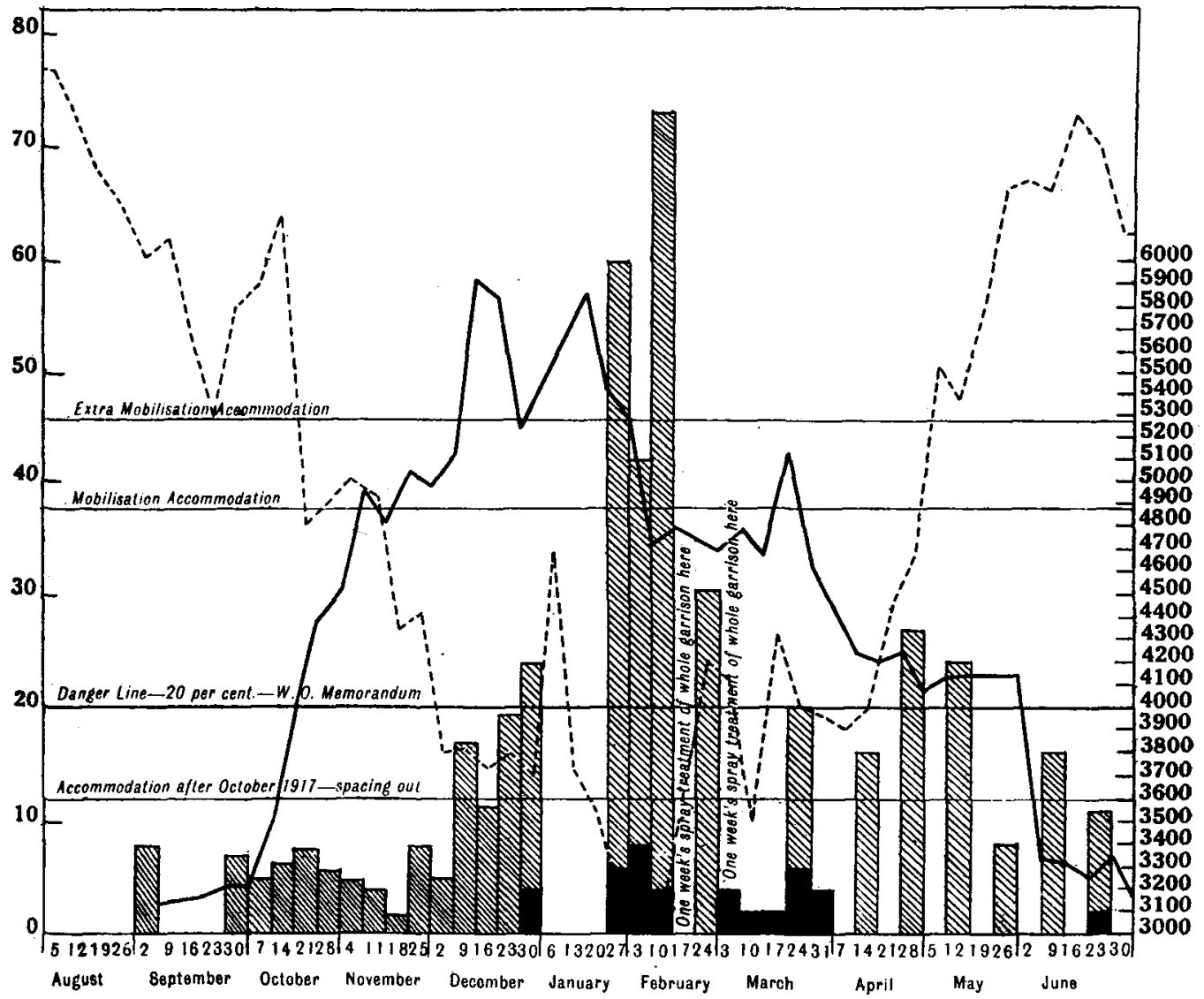

and they are then drafted to the respective reserve battalions of the five regiments, in various places. Most of the population is therefore floating, it abides three months, and passes. There is, however, a permanent staff of instructors, and two trained soldiers are in each barrack-room or hut. This arrangement may have an important bearing on the transmission of the infection from season to season. 


\section{PREVIOUS OUTBREAKS OF THE DISEASE.}

Cerebro-spinal fever first appeared at the depot in the early part of 1915, following a period of severe overcrowding due to the recruiting situation of that time.

Nineteen cases occurred at the depot, with eleven deaths, followed by ten cases with six deaths in the various barracks of the reserve battalions and in a camp fed by the depot.

No differentiation of types of the meningococci was attempted in these cases, as Lt.-Col. Gordon's work was not then published.

In February, $1916^{1}$, cerebro-spinal fever reappeared at the depot, and between February and April seven cases occurred. These were all due to the Type II meningococcus. The patients all recovered.

From the occurrence of the first case, a very thorough investigation not only of contacts of the cases, but also of contacts of the positive contacts, was carried out by Capt. Flack. This revealed a contact carrier-rate of

$21 \%$ in February (113 men examined contacts of one case),

$9 \%$ in March (219 men contacts of four cases),

$20.5 \%$ in April (39 contacts of one case), and

$6 \%$ in May ( 60 contacts of one case).

In every case and in every carrier meningococcus Type II was found.

The undisputed predominance of Type II in cases and contacts is most striking.

All positive contacts thus discovered were forthwith isolated. No cases occurred during this season in the reserve battalions.

\section{BEFORE THE EPIDEMIC OF 1917. THE AUTUMN OF 1916.}

In August a large non-contact sample was taken by Capt. Flack by swabbing 121 men who had been three months in the depot. He found a carrier-rate of $10 \%$, an unexpectedly high figure, especially for the time of year.

He therefore decided to keep a continuous watch upon the carrierrate by means of large weekly swabbings, as he anticipated a return of the disease in the following winter.

The aggregate swabbings in September showed a carrier rate of $5 \%$, in October $6 \%$ and in November $4.6 \%$. So far all seemed well.

\footnotetext{
1 Capt. M. Flack, Special Report, Medical Research Committee, No. 3.
} 
The depot was, however, rapidly filling up, as a result of the operation of the National Service Acts, and in the first week of November was for the first time above its "mobilisation" accommodation.

On December 4th a number of Aylwin huts were occupied for the first time. On December 9th the overcrowding was at its zenith, over a thousand men more than the ordinary "mobilisation" strength and 600 more than the "extra mobilisation" strength being accommodated in drill sheds, etc., as well as the Aylwin huts.

On December 11th, an epidemic of German measles was fairly established, and from this date carriers detected by sampling were isolated in huts in the depot, instead of being sent to the carrier centre, which was full.

The carrier-rate, which had kept beautifully low during November ( $5 \%$ on November 29th), now commenced to rise in ominous fashion; on December 6th it was nearly $17 \%$, on the 21 st $19 \%$, just under the $20 \%$ danger line as laid down in the War Office memorandum.

The carrier-rates are shown upon the Chart $A$ and details of the non-contact samples before the epidemic are seen below.

Period before the commencement of the Epidemic.

\begin{tabular}{|c|c|c|c|c|c|c|c|c|}
\hline \multirow[b]{2}{*}{ Date } & \multirow{2}{*}{$\begin{array}{l}\text { Non-contact } \\
\text { sample or } \\
\text { contact }\end{array}$} & \multirow[b]{2}{*}{$\begin{array}{l}\text { No. } \\
\text { swabbed }\end{array}$} & \multirow[b]{2}{*}{$\begin{array}{c}\text { No. } \\
\text { positive }\end{array}$} & \multirow[b]{2}{*}{$\begin{array}{l}\text { Carrier } \\
\text { rate \% }\end{array}$} & \multicolumn{4}{|c|}{ Types } \\
\hline & & & & & I & II & III & IV \\
\hline Sept. 7 & Sample & 127 & 10 & 8 & 3 & 3 & - & 4 \\
\hline$\Rightarrow 14$ & " & 123 & 1 & .75 & - & I & - & - \\
\hline " 25 & " & 119 & 7 & 6 & - & 5 & 2 & - \\
\hline Oct. 2 & " & 120 & 5 & 4 & 1 & 3 & 1 & - \\
\hline " $\quad 9$ & , & 139 & 9 & $6 \cdot 5$ & 4 & 4 & 1 & - \\
\hline " 16 & , & 118 & 9 & $7 \cdot 5$ & 4 & 4 & 1 & - \\
\hline , 23 & " & 117 & 7 & 6 & 2 & 4 & 1 & - \\
\hline " 30 & " & 121 & 6 & 5 & - & 3 & 3 & - \\
\hline Nov. 5 & , & 90 & 3 & $3 \cdot 25$ & 2 & - & 1 & - \\
\hline , 13 & , & 115 & 2 & 1.75 & 2 & - & - & - \\
\hline , 22 & ", & 113 & 9 & 8 & 3 & 1 & 5 & - \\
\hline , 29 & $"$ & 120 & 6 & 5 & 2 & 3 & 1 & 一 \\
\hline Dec. 6 & " & 120 & 20 & 16.75 & 2 & 17 & - & 1 \\
\hline , 13 & ", & 119 & 14 & 12 & 12 & 2 & - & - \\
\hline \#21 & , & 125 & 24 & $19 \cdot 25$ & 3 & 20 & 1 & - \\
\hline , 29 & , & 91 & 10 & 11 & 1 & 9 & - & - \\
\hline
\end{tabular}

IV. THE EPIDEMIC.

Just at the end of the year, all the requisite factors for an epidemic of cerebro-spinal fever were present, cold weather, severe overcrowding, a high carrier rate, and a population rendered susceptible by youth, 
by strange surroundings and methods of life, and by the depressing effects of nostalgia combined with the malaise of anti-typhoid inoculations and vaccination performed before acclimatisation to their new circumstances was established.

The first case was diagnosed on December 29th, and was almost immediately followed by one other. The contacts (73) of these two cases showed carrier rates of 23 and $27 \%$ respectively. Both were due to Type II meningococcus, seventeen out of twenty positive contacts carrying the same type.

No further cases occurred for three weeks, and owing to the unfortunate illness of Captain Flack, no samples of non-contacts were taken during this period. Captain W. Allan then took over the work for a few weeks, until he also became ill; his observations are those recorded from January 24th to February 19th inclusive.

During the same three weeks the Aylwin huts, which had been leaking badly, were given up, and five hundred men were sent away from the depot to ease the overcrowding. Influenza of a mild type and bronchial catarrhs became increasingly prevalent.

Between January 24th and February 2nd seven cases occurred in succession, three of them being fulminating cases, the patients dying within twenty-four hours of the onset. Of these cases, 185 contacts were swabbed showing a carrier-rate of $46 \%$.

The first of these cases was due to Type I meningococcus, the rest were all due to Type II.

The contacts of the first case showed a carrier-rate of $43 \%$, those of the second reached the appalling rate of $71 \%$, the hut containing 32 men, one of whom was the patient (Type II), ten of whom were carriers of Type I, eleven of Type II, one of Type III. Six of the nine remaining had organisms resembling meningococci which failed to agglutinate with the standard sera, only three were above suspicion.

A sample of non-contacts taken on February 5th showed the even higher rate of $72.5 \%$, the trained soldiers being almost as heavily infected as the recruits. The period of this group of cases exactly coincides with the great frost-the severest weather experienced in England since 1895 .

It was now obvious that a severe epidemic was threatened, and the question of swabbing the whole garrison and isolating all carriers was discussed and negatived on account of the magnitude of the work, and the practical certainty that half the population was carrying.

Instead, the following measures were taken: parades were shortened, 
inoculation and vaccination stopped, men were spread out as much as possible (numbers were now slightly below "mobilisation" scale of accommodation), a certain number of windows in each hut and room were fixed open, and the crowding of Y.M.C.A.'s etc., was limited.

It was also determined to subject the entire population to treatment with Levick steam sprays, using $1 \%$ zinc sulphate dissolved in normal saline. Four huts were adapted using eight Levick sprays, each hut having a small central portion partitioned off to form an inhaling chamber of some 1800 cubic feet and containing two Levick sprays, the portions of the hut on either side served respectively as an antechamber to prevent loss of vapour, and as a cooling-off room. The latter was warmed by stoves and the men remained in it seven minutes after being seven minutes in the inhaling chamber. Every man in the depot was thus treated for seven consecutive days.

After a two days' interval the camp was systematically sampled.

\section{Results of Sample Swabbings after One Week's Spraying.}

\begin{tabular}{|c|c|c|c|c|c|c|c|c|}
\hline \multirow[b]{2}{*}{ Date } & \multirow[b]{2}{*}{ Regiment } & \multirow{2}{*}{$\begin{array}{l}\text { No. } \\
\text { swabbed }\end{array}$} & \multirow{2}{*}{$\begin{array}{c}\text { No. } \\
\text { positive }\end{array}$} & \multirow{2}{*}{$\begin{array}{l}\text { Carrier } \\
\text { rate \% }\end{array}$} & \multicolumn{4}{|c|}{ Types } \\
\hline & & & & & $\overline{\mathbf{I}}$ & II & III & $\mathbf{I V}$ \\
\hline 19. 2.17 & A & 50 & 15 & 30 & 0 & 14 & 0 & 1 \\
\hline 19. 2.17 & B & 50 & 11 & 22 & 1 & 10 & 0 & 0 \\
\hline 22.2 .17 & $\mathrm{C}$ & 50 & 12 & 24 & 2 & 9 & 0 & 1 \\
\hline 22. 2.17 & D & 50 & 18 & 36 & 8 & 8 & 0 & 2 \\
\hline \multirow[t]{3}{*}{ 24. 2.17} & $\mathbf{E}$ & 50 & 21 & 42 & 4 & 17 & 0 & 0 \\
\hline & Total & 250 & 77 & $30 \cdot 8$ & 15 & 58 & 0 & 4 \\
\hline & & $\begin{array}{l}\text { Total nu } \\
\text { Total nu }\end{array}$ & $\begin{array}{l}\text { swabbed } \\
\text { positive }\end{array}$ & $\begin{array}{r}250 \\
77\end{array}$ & & & & \\
\hline
\end{tabular}

Feb. 19-24. Carrier rate (after spraying) $30 \cdot 8 \%$.

The general carrier-rate, therefore, had fallen from over $60 \%$ to $30.8 \%$. This was encouraging but still too high, and all the garrison were again submitted to a week's course of spraying beginning February 28 th, 1917.

The general use of the steam spray was then discontinued and on March 7th only freshly joined recruits were sprayed during their first week in the depot.

On March 22nd another sampling was done, the result being:

\begin{tabular}{|c|c|c|c|c|c|c|c|c|}
\hline \multirow[b]{2}{*}{ Date } & \multirow[b]{2}{*}{ Regiment } & \multirow[b]{2}{*}{$\begin{array}{c}\text { No. } \\
\text { swabbed }\end{array}$} & \multirow[b]{2}{*}{$\begin{array}{c}\text { No. } \\
\text { positive }\end{array}$} & \multirow[b]{2}{*}{$\begin{array}{l}\text { Carrier } \\
\text { rate \% }\end{array}$} & \multicolumn{4}{|c|}{ Types } \\
\hline & & & & & I & II & III & IV \\
\hline 22. 3. 17 & $\begin{array}{c}B \text { and } C \\
23 \text { of each }\end{array}$ & 46 & 9 & 20 & 5 & 4 & 0 & 0 \\
\hline
\end{tabular}


The contacts of these cases swabbed upon the same day showed a carrier rate of $31 \%$.

The last two cases of the epidemic occurred on the same day: March 27th, and in the same hut. This was the only occasion in which any apparent connexion between patients occurred, but the population of this hut showed a carrier-rate of only $7 \%$, but two carriers of Type II being discovered, although all were twice examined on different days This was in regiment "C."

Nine cases occurred during March, making nineteen in all during the epidemic; there was also one case in which the diagnosis was doubtful

Of the undoubted cases, one only was due to meningococcus Type I thirteen were due to Type II, and in five cases growth was not obtained owing either to the death of the patient in the fulminating cases, or tc the chilling of the specimen taken late at night in the cold, and on the long journey to the laboratory.

Cases were fairly evenly distributed amongst the regiments in pro. portion to their strength. " $\mathrm{C}$," a Scottish regiment, had comparatively low carrier-rates throughout, whilst "D," an Irish regiment, had higl carrier rates and no cases at all.

One additional sporadic case (due to Type I) occurred on June 20th

\section{CONTACTS.}

During the time of the general spraying, examination of the contact: of six cases was not done, as all were being treated, and in view of the high carrier-rate prevailing throughout the depot, which was quaran tined, isolation of these contacts was not practised.

Of the other fourteen cases (including the doubtful case) 426 contact: were examined, 145 of whom were found positive: $71 \%$ of the positiv contacts carried Type II meningococcus.

It is, however, both interesting and important to note, that if th total contact swabbings during the epidemic be compared with th total non-contact sample swabbings during the period of the epidemic it will be found that the average carrier-rate is the same, $34 \%$ in eacl case. It will also be seen that these totals show nearly the same pro portion of Type I and Type II.

The following table shows a summary of the three periods:

I. The autumn months prior to the occurrence of the first case of December 29th.

II. The epidemic period December 29th to the end of March, bot] contact, and non-contact. 
III. The quarter April 1st to June 30th immediately following the epidemic during which samples have been taken at regular intervals.

Summary of Periods.

\section{Period}

I. September to Dec. 29th. All non-contact

II. Period of epidemic, December 29th to March 31st. Contacts (Samples) non-contacts

III. Quarter after epidemic, April lst to June 30th

\begin{tabular}{ccccccccc}
$\begin{array}{c}\text { No. } \\
\text { swabbed } \\
1877\end{array}$ & $\begin{array}{c}\text { No. found } \\
\text { positive } \\
142\end{array}$ & $\begin{array}{c}\text { Carrier } \\
\text { rate } \%\end{array}$ & $\begin{array}{c}\text { I } \\
426\end{array}$ & 145 & 34 & II & III & IV \\
& & & 38 & 103 & 2 & 2 \\
336 & 115 & 34 & 31 & 78 & 2 & 4 \\
669 & 102 & $15 \cdot 3$ & 16 & 76 & 9 & 1 \\
\hline 3308 & 504 & $15 \cdot 2$ & 126 & 336 & 30 & 12
\end{tabular}

\section{Details of all examinations during Epidemic Period.}

\begin{tabular}{|c|c|c|c|c|c|c|c|c|c|c|}
\hline \multirow{2}{*}{\multicolumn{2}{|c|}{ Date }} & \multirow[b]{2}{*}{ Description } & \multirow[b]{2}{*}{$\begin{array}{l}\text { Number } \\
\text { swabbed }\end{array}$} & \multirow[b]{2}{*}{$\begin{array}{l}\text { Number } \\
\text { positive }\end{array}$} & \multirow[b]{2}{*}{$\begin{array}{l}\text { Carrier } \\
\text { rate } \%\end{array}$} & \multicolumn{3}{|c|}{ Types } & \multicolumn{2}{|r|}{$\begin{array}{l}\text { Percentage } \\
\text { carrying gram } \\
\text { negative cocci } \\
\text { failing to }\end{array}$} \\
\hline & & & & & & I & II & III & IV & $\begin{array}{l}\text { failing to } \\
\text { agglutinate }\end{array}$ \\
\hline Dec. & 29 & $\begin{array}{l}\text { Contacts with a case } \\
\text { of Type II }\end{array}$ & 30 & 7 & 23 & - & 5 & 1 & 1 & 47 \\
\hline Jan. & 4 & $\begin{array}{l}\text { Contacts with a case } \\
\text { of Type II }\end{array}$ & 44 & 13 & 27 & $\mathbf{I}$ & 12 & - & - & 41 \\
\hline$"$ & 24 & $\begin{array}{l}\text { Contacts with a case } \\
\text { of Type I }\end{array}$ & 30 & 13 & 43 & 2 & 11 & - & - & $40 \cdot 5$ \\
\hline ", & 26 & $\begin{array}{l}\text { Contacts with a case } \\
\text { of Type II }\end{array}$ & 31 & 22 & 71 & 10 & 11 & 1 & - & $19 \cdot 5$ \\
\hline$"$ & 29 & $\begin{array}{c}\text { Contacts } \\
\text { case }\end{array}$ & 28 & 14 & 50 & 4 & 10 & - & 一 & 25 \\
\hline$"$ & 31 & $\begin{array}{l}\text { Contacts case Type } \\
\text { unknown }\end{array}$ & 26 & 6 & 23 & - & 6 & 一 & - & 73 \\
\hline Feb. & 2 & $\begin{array}{c}\text { Contacts Type II } \\
\text { case }\end{array}$ & 32 & 10 & 31 & 5 & 5 & - & - & $46 \cdot 75$ \\
\hline ," & 6 & ", & 26 & 17 & 65 & 2 & 14 & - & 1 & 8 \\
\hline " & 5 & Non-contacts sample & 40 & 29 & $72 \cdot 5$ & 11 & 16 & 2 & 一 & 20 \\
\hline , & 19 & , & 250 & 77 & $30 \cdot 75$ & 15 & 58 & - & 4 & $5 \cdot 25$ \\
\hline March & 17 & Contacts II case & 26 & 2 & $7 \cdot 75$ & 一 & 2 & 一 & - & $15 \cdot 25$ \\
\hline ", & 22 & $"$ & 29 & 7 & 24 & 6 & 1 & - & - & 21 \\
\hline " & 22 & $"$ & 68 & 20 & $29 \cdot 5$ & 7 & 13 & - & - & 25 \\
\hline ", & 23 & $\begin{array}{l}\text { Contacts with a case } \\
\text { Type unknown }\end{array}$ & 28 & 12 & $42 \cdot 75$ & 1 & 11 & - & $一$ & $14 \cdot 25$ \\
\hline ", & 22 & Non-contacts sample & 46 & 9 & 20 & 5 & 4 & - & - & 32 \\
\hline " & 28 & Contacts II cases (2) & 28 & 2 & 7 & - & 2 & - & 0 & 7 \\
\hline Totals & & $\begin{array}{l}\text { Contacts ... } \\
\text { Non-contacts }\end{array}$ & $\begin{array}{l}426 \\
336\end{array}$ & $\begin{array}{l}145 \\
115\end{array}$ & $\begin{array}{l}34 \\
34\end{array}$ & $\begin{array}{l}38 \\
31\end{array}$ & $\begin{array}{r}103 \\
78\end{array}$ & $\begin{array}{l}2 \\
2\end{array}$ & $\begin{array}{l}2 \\
4\end{array}$ & \\
\hline
\end{tabular}


VI. CARRIERS OF GRAM-NEGATIVE DIPLOCOCCI, WHICH ARE CULTURALLY INDISTINGUISHABLE FROM MENINGOCOCCI BUT WHICH FAIL TO AGGLUTINATE WITH ANY ONE OF THE FOUR STANDARD SERA.

A careful record has been kept of the percentage of men who carry organisms resembling on culture the meningococcus.

A comparison of the carrier rates of such men with the carrier rates of carriers of the serologically proved meningococcus shows some interesting points.

During the autumn period prior to the epidemic the proportion of agglutinating organisms to non-agglutinating strains was quite small, usually about one-sixth, often less and going as low as one-twentieth.

During the epidemic period, as the carrier-rate rose, this proportion rose rapidly too, in non-contact samples equally with contacts, the agglutinable cocci now forming two-thirds, three-quarters, or even more of the whole.

This proportion was maintained for some time and sank much more slowly than it had risen. The proportion was not diminished by steam spray treàtment. Thus, in the sample immediately before the treatment was commenced, of forty men thirty-seven $(92.5 \%$ ) carried organisms resembling the meningococcus; of these thirty-seven, twenty-nine (72.5\% of the whole) agglutinated (eleven Type I, sixteen Type II, two Type III), whilst eight failed to agglutinate.

In the sample taken two days after the first week of spray treatment of $250 \mathrm{men}, 91(36.4 \%)$ carried meningococcus-like organisms. In seventy-seven $(30.75 \%$ ) agglutination was positive (fifteen Type I, fifty-eight Type II, four Type IV), whilst only fourteen failed.

The steam spray treatment reduced the just and the unjust alike.

These observations seem to lead to one important practical point, cultural characteristics are a much more reliable guide with a high carrier-rate, and during an epidemic, than they are with a low carrierrate in a non-epidemic period.

The method of diffusion of these non-agglutinating organisms is probably exactly similar to that of the meningococcus.

Flavus agglutination has been given throughout the Chart and Table as negative. 
Chart B. 1917 Epidemic Cerebro-Spinal Fever. " $X$ ” Depot.

Relative percentages of:

1. Carriers of gram-negative cocci morphologically indistinguishable from meningococci but not qualifying serologically as such-shaded columns,

2. Carriers of meningococci serologically proved-plain columns.

Showing the greatly increased proportion of the latter during the Epidemic Period.

Period of low carrier rate Autumn

Epidemic period

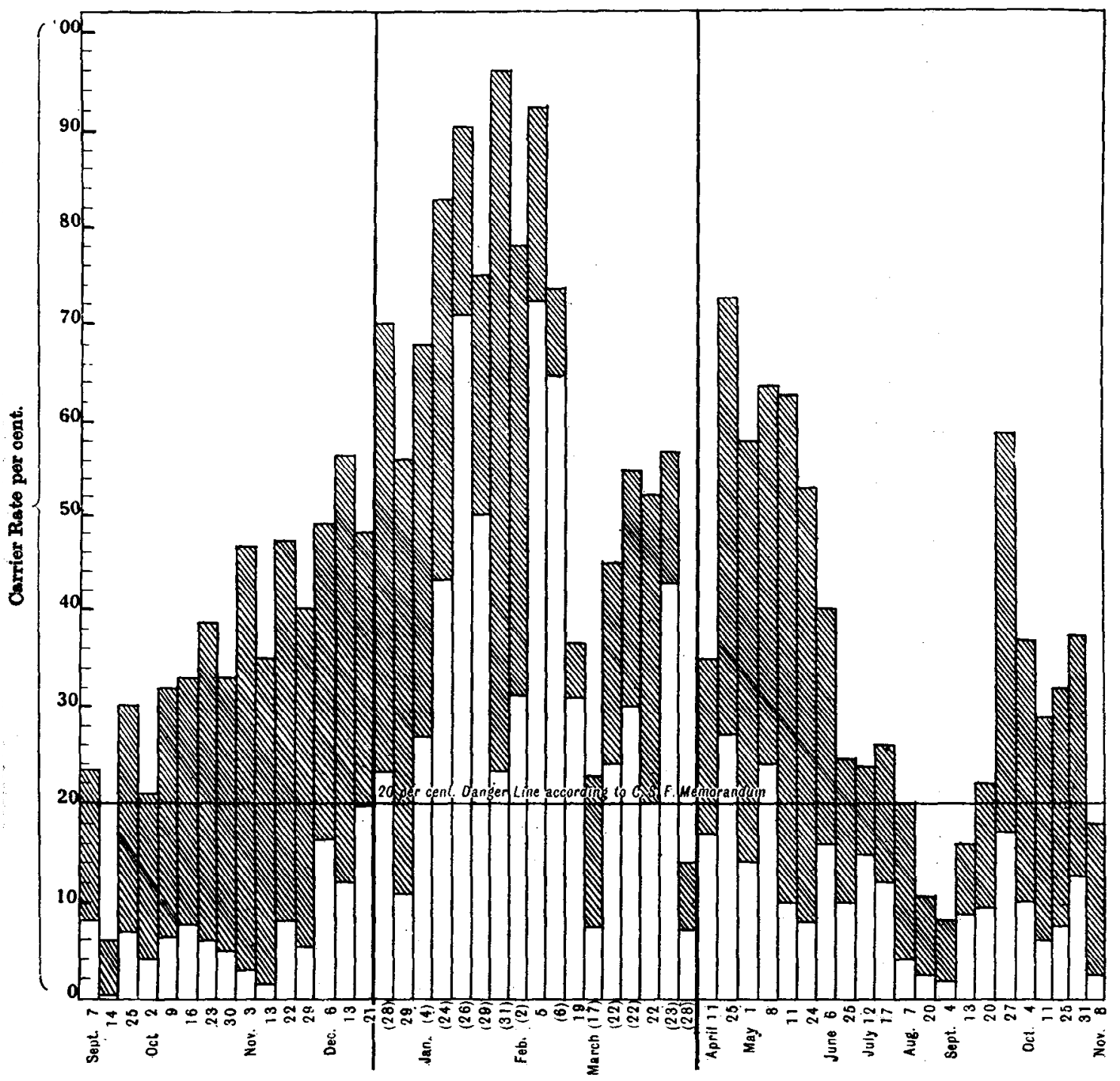

Dates in parentheses $=$ contacts of cases, thus: Jan. (4).

Plain dates $=$ sample swabbings. 
Carrier-rates per cent. of:

I. All organisms morphologically resembling the meningococcus.

II. True meningococcus, i.e. those which agglutinate with any one of the four standard types.

III. Inagglutinables with standard sera.

I.

Contacts

(usually 30)

Date of swabbing

Sept. 7

, 14

"25

Oct. 2

, 9

, 16

, 23

, 30

Nov. 5

" 13

" 22

, 29

Dec. 6

, 13

, 21

" 29

Dec. 29

Jan. 4

" 24

, 26

, 29

"31

Feb. 2

" 6

, 5

" 19

March 17

" 22

" 22

" 23

" 22

, 28

April 11

" 25

May 1

" 8

" 11

" 24

June 6

, 25 or non-contacts usually 100-120 men

Non-contacts

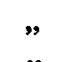

",

"

"

,"

,

$"$

,"

"

",

,"

,"

,

,

"

6

30

$21 \cdot 5$

32

33

33

35

47

40

49

48

56

Contacts
$"$,
$"$,
Non-contacts
Contacts
,$"$
"
"
Non-contacts
Contacts

52

14

Non-contacts

35
Percentage carriers of all organisms, resembling meningococeus $23 \cdot 5$

$38 \cdot 5$

$46 \cdot 5$

$56 \cdot 5$

II.

Real carrier rate: percentage carrying agglutinable meningoeocei

8

.75

7

4

$6 \cdot 5$

$7 \cdot 5$

6

5

$3 \cdot 25$

$1 \cdot 75$

8

5

$16 \cdot 75$

12

$19 \cdot 25$

II

Epidemic period begins here

70
68
$83 \cdot 5$
$90 \cdot 5$
75
96
78
73

23

27

43

71

50

23

$31 \cdot 25$

65

$72 \cdot 5$

$30 \cdot 75$

$7 \cdot 75$

24

29.5

$42 \cdot 75$

20

7

Epidemic period ends

17

27

14

24

10

8

16

10
III.

Percentage carrying nonagglutinable cocci

15.5

$5 \cdot 25$

23

$17 \cdot 5$

$25 \cdot 5$

$25 \cdot 5$

$32 \cdot 5$

28

$43 \cdot 25$

$33 \cdot 25$

39

35

32.25

43.5

28.75

45

47

41

$40 \cdot 5$

19.5

25

73

$46 \cdot 75$

8

20

5.25

$15 \cdot 25$

21

25

$14 \cdot 25$

32

7

18

$45 \cdot 5$

44

40

53.5

45

24

15 


\section{AFTERMATH OF THE EPIDEMIC.}

The carrier-rate of the depot remained high up to August when it dropped suddenly and reached the nadir of $2 \%$, which may be regarded as the irreducible minimum.

In July it had reached $15 \%$ and large drafts being sent to the various reserve battalions, some of whose barracks were in a very crowded condition, a rather alarming series of events occurred.

At the barracks of " $\mathrm{C}$ " regiment (which, it will be remembered, had been characterised by a somewhat low carrier-rate and its correct proportion of cases (4) to its strength at the depot) a sub-epidemic of three cases with two deaths occurred in September.

All the cases were in the same block of the barracks, an old building of bad design and with bad ventilation. All the patients had come within a few weeks from the depot at X. All suffered from the invasion of Type II meningococcus. The contacts and a large sample showed a carrier-rate of $11 \%$.

After these cases, samples were taken of the reserve battalions of " $A$ " and " $B$ " regiments, whose barracks were 22 miles apart. In both there was considerable overcrowding. The barrack-room sample of "A" showed the alarming figure especially for early October of $28 \%$, one large room reaching the appalling rate (for the season) of $38.75 \%$. "B" showed the high figure for barrack-rooms of $22 \%$ (September 29th) and of $16 \%$ for men under canvas (October 6th). On each occasion, 100 men were sampled.

The reserve battalion of " $D$ " under ideal barrack-room conditions (November 16th) gave a carrier-rate of $6 \%$, and the reserve battalion of " $E$ " under only fair conditions, somewhat crowded in a mixture of billets, huts and stables had $13 \%$.

How closely the meningococcus carrier-rate is correlated to overcrowding is shown not only by the A Chart for the depot (black line), but by the experience with these reserve battalions.

" $A$ " having had to furnish large drafts is now comparatively well accommodated and is almost down to peace strength accommodation ( 60 feet floor space per man). Beds have been spaced out and the carrierrate on November 23rd was just a quarter (7\%) of what it was on October 2nd, whilst the large room that had the $38 \%$ carrier-rate, when badly crowded, has now but $4.5 \%$.

Fortunately, no further cases of the disease have occurred attributable to the depot epidemic. 





These high carrier-rates have been largely due to an autumnal renaissance of Type $\mathrm{I}$, a phenomenon seen on a smaller scale last year. The three cases, however, were all due to Type II.

\section{SUMMARY.}

(1) There were nineteen cases and eight deaths at the depot during the epidemic.

One doubtful case during this period recovered, and a sporadic case in June due to Type I also recovered; these are not included in the above, nor is one man who went on leave to Blackpool, and developed the disease (Type II) on arrival.

(2) So far the reserve battalions have had three cases only, with two deaths, although a high carrier-rate wave has been detected in two.

(3) All the cases (except the June case) at the depot occurred during exceptionally cold weather. In the chart the cases appear to lie in the trough of a great depression of the curve of mean weekly temperature (broken line). They also follow immediately upon exceptional crowding (black line).

(4) There was a well-marked premonitory rise in the carrier-rate in December 1916, before the first case occurred, and an enormous rise before the epidemic was really established.

The carrier-rate, which was $19 \cdot 25 \%$ on December $23 \mathrm{rd}$, reached what is usually considered the danger point of $20 \%$ (see War Office Memorandum on Cerebro-spinal Fever, page 2) just six days before the first case occurred.

It would appear that estimations of the carrier-rate by means of large sample swabbings afford a reliable warning of the imminence or danger of an epidemic.

(5) The cases in the epidemic were nearly all due to the meningococcus of Type II, the organism present in the outbreak of 1916.

The rise in the carrier-rate was also chiefly due to the increase of carriers of this type. Freshly joined recruits showed few carriers at all and very few Type II carriers when swabbed before having slept in the barracks.

(6) During the epidemic, the carrier-rate among non-contacts was substantially the same as amongst the actual contacts of cases, averaging $34 \%$ for the period, in each case.

(7) The proportion of agglutinable strains to inagglutinable strains of organisms morphologically indistinguishable from the meningococcus increased very markedly during the epidemic period. 
(8) The treatment of the whole population by the steam zinc sulphate solution spray (which was carried out daily for two seven-day periods with an interval of a fortnight), was followed by a satisfactory drop in the carrier-rate, and by a temporary cessation of cases on each occasion.

(9) $60 \%$ of the actual patients suffering from the disease were in their first month of service.

$40 \%$ of the patients had either been inoculated or vaccinated within seven days of onset (three on the same day); $60 \%$ within a fortnight.

(10) Previous and concurrent epidemics of Germar measles, influenza and bronchitis had helped (by causing coughing and sneezing and by lowering vitality) to produce the great rise in the carrier-rate, which culminated in the case epidemic.

\section{PROPHYLAXIS FOR 1918.}

The carrier-rate in August dropped to $2 \%$. This was evidently the acceptable time to try to prevent by early measures a return for the fourth time of the disease in the coming winter.

Accordingly, following the lessons, bacteriological and otherwise, of the 1917 epidemic, a scheme was produced by the kind help and cooperation of the Commandant of the depot, and of the Senior Medical Officer. It received the permission and the backing of the authorities, particularly the very kind and prompt help of the D.D.M.S. and the S.S. O. of the District, after it had been submitted to the valuable advice and criticisms of Lt.-Col. Gordon of the Central Cerebro-spinal Fever Laboratory.

It has been carried out in excellent time and awaits, with some trepidation, it must be confessed; the verdict of the coming winter.

The chief prophylactic measures are:

1. Spacing out of beds to a minimum interval between beds of $2 \frac{1}{2}$ feet. To do this means a reduction of 1266 beds under mobilisation standard.

The depot, being much less full than last year, the extra accommodation was obtainable, the chief difficulty being that extra huts occupied meant extra fuel, and fuel is issued on a scale of men and not of huts occupied.

This difficulty, however, was soon overcome by the recommendation of the D.D.M.S. and no hut has now more than twenty-four beds compared with thirty-two last year. 
The difference in the general amenities of life is very striking, and the comfort and appearance of the huts is much increased, apart from the diminished risk of the spread of any catarrhal diseases.

No barrack-room has now more than twenty-six beds in it.

2. Special ventilation is being arranged, four windows in each hut are being fixed open $\left(15^{\circ}\right)$ with hopper sides, and with a prolongation of the outside weather boarding to give an upward direction to the air and to prevent driving rain and snow from entering.

Four windows are also being fixed slightly open in each barrackroom.

3. During the danger months December to March, anti-typhoid inoculation is to be done in the second month with fourteen days between doses, vaccination is done in the first month, great care being taken, as was done previously, during the period of vaccinia malaise.

4. A but has been adapted as a special spray chamber with an external boiler and twenty Hine's jets under the direction and supervision of Major Hine himself.

This is capable of spraying 120 men simultaneously and can be filled with spray vapour in two minutes. The atmosphere is not vitiated by the fumes of the burning spirit as with the Levick spray; it remains quite cool and pleasant.

It is proposed to spray each of the five regiments in rotation every day for six days once a month, if any rise takes place in the carrierrate sufficient to appear a warning.

It is also proposed to spray all recruits on entry for their first six days, and, if the carrier-rate of the depot be higher than that of the reserve battalion (at present it is lower), to spray all drafts leaving the depot.

5. The medical inspection premises are to be enlarged. Every recruit has to go to these at least four times for examination, vaccination and two inoculations. During the last epidemic, the premises, being most inadequate, were always very crowded, and probably a fruitful source of infection. Practically all the nurses and orderlies working in them, became temporary carriers during the epidemic.

6. A large sample swabbing (100 men) is taken weekly and affords a guide to the current carrier-rate. 